\title{
Additive Interaction of Cisplatin and Histone Deacetylase Inhibitors Combined Treatment in Rhabdomyosarcoma Cells - An Isobolographic Analysis
}

\author{
AGATA JARZĄB ${ }^{1}$, JAROGNIEW J. ŁUSZCZKI ${ }^{2}$, MAŁGORZATA GUZ ${ }^{1}$, \\ EWELINA GUMBAREWICZ ${ }^{1}$, KRZYSZTOF POLBERG ${ }^{3}$ and ANDRZEJ STEPULAK ${ }^{1}$ \\ ${ }^{1}$ Department of Biochemistry and Molecular Biology, Medical University of Lublin, Lublin, Poland; \\ ${ }^{2}$ Department of Pathophysiology, Medical University of Lublin, Lublin, Poland; \\ ${ }^{3}$ Department of Otolaryngology, MSWiA Hospital, Lublin, Poland
}

\begin{abstract}
Background/Aim: The aim of this study was to assess the anticancer effect and the type of pharmacologic drug-drug interaction of cisplatin (CDDP) and histone deacetylase inhibitors (HDIs) combined treatment on the rhabdomyosarcoma cell line. Materials and Methods: The antiproliferative actions of cisplatin and suberoylanilide hydroxamic acid (SAHA, vorinostat), as well as valproic acid (VPA) alone and in combination, were evaluated using the tetrazolium dye-based MTT cell proliferation assay and isobolographic analysis. Results: All tested compounds inhibited proliferation of rhabdomyosarcoma cancer cells in a dose-dependent manner. The combinations of CDDP with SAHA and CDDP with VPA produced additive interaction with type-I isobolographic analysis. Conclusion: When adding SAHA or VPA to CDDP therapy, one can expect additive anticancer effects in the rhabdomyosarcoma cell line.
\end{abstract}

Rhabdomyosarcoma (RMS) is the most frequent childhood sarcoma of soft tissues (1). It originates from mesenchymal stem cells and can be found either as primary neoplasm or as a component of a heterogenous malignancy. Four histological subtypes of RMS are distinguished including alveolar rhabdomyosarcoma (ARMS), embryonal rhambdomyosarcoma (ERMS), pleomorphic rhamdomyosarcoma and sclerosing/ spindle cell rhabdomyosarcoma (2). Unfortunately, patients with RMS have a poor prognosis caused by late diagnosis, metastasis and local recurrence (3). Multimodal therapy of

Correspondence to: Professor Andrzej Stepulak, Department of Biochemistry and Molecular Biology, Medical University of Lublin, ul. Witolda Chodzki 1, 20-093 Lublin, Poland. Tel: +48 81448 6350, Fax +48 81448 6350, e-mail: andrzej.stepulak@umlub.pl

Key Words: Rhabdomyosarcoma, cisplatin, histone deacetylase inhibitors, VPA, SAHA, isobolographic analysis.
RMS includes chemotherapy combined with surgery and radiotherapy. One of chemotherapeutics used in the treatment of RMS is cisplatin (CDDP). Platinum complexes crosslink with DNA strands, which ultimately triggers cells to die in a programmed way. Cisplatin (CDDP) treatment of cancers activate several molecular mechanisms that induce apoptosis including oxidative stress, induction of p53 signalling and cellcycle arrest, down-regulation of proto-oncogenes, and antiapoptotic protein (4). Unfortunately, cisplatin (CDDP) treatment display a number of side-effects that limit its clinical use (5). In order to overcome drug-resistance and reduce toxicity combination therapies of cisplatin with other cancer drugs (4) or natural compounds (6-8) constitute an alternative therapeutic approach.

New chemotherapeutics, which could be applied for RMS treatment, are histone deacetylases inhibitors recently introduced to clinical use for treatment of certain cancer types. HDIs are responsible for regulation of gene transcription through chromatin remodeling. They block histone deacetylation which allows to restore pathways silenced in cancer cells, leading to cell-cycle arrest, apoptosis or changes in cancer cells differentiation (9). HDIs exhibit anti-proliferative activities to various types of cancer cells both in vitro and in vivo (10). On the other hand they have relatively low toxicity against normal cells (11).

One of HDIs, which is used alone or in combination with other anticancer drugs, is vorinostat (SAHA) which was approved by the U.S.A. FDA in October 2006 for the treatment of refractory cutaneous T-cell lymphoma (12). Vorinostat has been proven to inhibit growth of lymphoma (13), acute myeloid leukemia (14), myelodysplastic syndrome (15), advanced melanoma (16) and advanced solid tumors (17). It was also found to suppress the growth and induce cell death of human RMS in vitro (18). Moreover, SAHA diminished embryonal rhabdomyosarcoma (ERMS) tumor growth and progression by inducing myogenic 
differentiation as well as reducing the self-renewal and migratory capacity of ERMS cells (19). SAHA also induced inhibition of cells proliferation and led to a significant radiosensitization of RMS tumor cell lines (20).

Valproic acid (VPA) is an approved drug and has been used in the treatment of epilepsy, manic-depressive disorders and migraines, as well as in cancer therapy, since its new molecular mechanism of action was discovered - the inhibition of histone deacetylases (21). VPA exhibits in vitro and in vivo antitumor activities against neuroblastoma (22), glioma (23), leukemia (24) and lymphomas (25). VPA was also found to have antitumor effects in solid tumors including breast cancer (26) gastric cancer (27) sarcoma (28) or non-small cell lung cancer (29) by inducing apoptosis, promoting cell cycle arrest, enhancing cell differentiation and tumorigenicity inhibition (10). VPA was shown to prevent formation of rhabdomyosarcoma tumors in Patched heterozygous mice model of RMS development (30).

In our study we aimed to test if the combination of SAHA or VPA with CDDP will have better therapeutic effect in TE671 rhabdomyosarcoma cells than the compounds applied alone, as well as to reveal the type of pharmacologic drugdrug interaction between CDDP and HDIs in RMS.

\section{Materials and Methods}

Cell culture. TE671, human rhabdomyosarcoma cell line was obtained from the European Collection of Cell Cultures (ECACC). Mycoplasma free cell culture was conducted in standard conditions $\left(37^{\circ} \mathrm{C}\right.$, in a humidified atmosphere with $\left.5 \% \mathrm{CO}_{2}\right)$ in DMEM/F12 Ham medium (Sigma - Aldrich, St. Louis, MO, USA) supplemented with $10 \% \mathrm{v} / \mathrm{v}$ fetal bovine serum and antibiotics penicillin $(100 \mathrm{~g} / \mathrm{ml})$ and streptomycin $(100 \mathrm{~g} / \mathrm{ml})$ (Sigma Aldrich).

Cells treatment. Cisplatin and VPA were purchased from Sigma Aldrich, whereas SAHA was from Cyman Chemical (Ann Arbor, MI, USA). Cisplatin and VPA were dissolved in phosphate buffered saline (PBS) with $\mathrm{Ca}^{2+}$ and $\mathrm{Mg}^{2+}$, and SAHA was solubilized in dimethyl sulfoxide (DMSO). Cells at optimized concentrations of $1,0 \times 10^{4}$ cells $/ \mathrm{ml}$ were incubated for $96 \mathrm{~h}$ with increasing concentrations of the VPA $(17-830 \mu \mathrm{g} / \mathrm{ml}$, equivalent to $0.1-5.0 \mathrm{mM})$, SAHA $(0,026-2,6 \mu \mathrm{g} / \mathrm{ml}$, equivalent to $0.0001-0,01 \mathrm{mM})$, or CDDP $(0,01-15 \mu \mathrm{g} / \mathrm{ml})$ to assess the $\mathrm{IC}_{50}$ concentration for each compound.

MTT assay. MTT assay was used to determine cell viability as described previously (31). The relative viability of the treated cells compared to that of the control cells was expressed as \% of cells viability.

Isobolographic analysis. Isobolographic analysis was performed as described previously (26), with the exception that TE671 cell line was used. Isobolography is a statistical method allowing the precise characterization of pharmacodynamic interaction between drugs in both, preclinical and clinical studies (32). To start isobolographic analysis of interaction between CDDP and SAHA or VPA, we measured the percent inhibition of cell viability per increasing doses of CDDP, SAHA and VPA used alone in the rhabdomyosarcoma cell line. Subsequently, the dose-response effects for each investigated anti-cancer compound (i.e., CDDP, SAHA, VPA) in the rhabdomyosarcoma cell line (TE671) were fitted with log-probit linear regression analysis as recommended by Litchfield and Wilcoxon (33). Log-probit method allowed to calculate median inhibitory concentrations $\left(\mathrm{IC}_{50} \mathrm{~s}\right)$ for CDDP, SAHA or VPA, when administered singly. The test for parallelism of dose-response effects for CDDP and SAHA or VPA, as described in more details in our previous studies $(26,34,35)$ revealed that CDDP had its doseresponse effect non-parallel to that of SAHA and VPA in the rhabdomyosarcoma cell line (TE671) measured by the MTT assay. The type of interactions between CDDP and SAHA or VPA in the cancer cell line TE671 was isobolographically analyzed according to the methodology described elsewhere (36). From the experimentally denoted $\mathrm{IC}_{50}$ values for the drugs administered alone, median additive inhibitory concentrations of the mixture of CDDP with SAHA or VPA at the fixed-ratio of 1:1 ( $\left.\mathrm{IC}_{50 \text { add }}\right)-$ i.e., concentrations of the mixture, which should theoretically inhibit cell viability in $50 \%$ were calculated as described earlier (34). Subsequently, the experimentally-derived $\mathrm{IC}_{50 \mathrm{mix}}$ at the fixed-ratio of 1:1 was determined based on the concentration of the mixtures of CDDP with SAHA or VPA, inhibiting $50 \%$ of cell viability in the cancer cell line (TE671) measured in vitro by the MTT assay. The separate concentrations of CDDP and SAHA or VPA in the mixture were calculated from, the $\mathrm{IC}_{50 \text { mix }}$ values by multiplying this value by the respective proportions of particular drugs. Additional information concerning the isobolographic analysis has been published elsewhere $(34,36)$.

Statistical analysis. The data were analyzed using GraphPad Prism software with one-way ANOVA and Tukey post hoc tests. $p<0.05$ was considered to indicate a statistically significant difference. Results were presented as mean \pm standard error of the mean (SEM). Log-probit analysis was used to determine the experimentallyderived $\mathrm{IC}_{50}$ and $\mathrm{IC}_{50 \text { mix }}$ values for CDDP, SAHA and VPA, when the drugs were administered alone or in combination for the fixedratio of 1:1 (33). Difference between the experimentally-derived $\mathrm{IC}_{50 \text { mix }}$ values for the mixture of CDDP with SAHA or VPA and the theoretically additive $\mathrm{IC}_{50}$ add values was statistically verified by using the unpaired Student's $t$-test, as presented elsewhere (36).

\section{Results}

HDI and CDDP elicit anti-cancer properties in rhabdomyosarcoma cell line. We have shown a decrease of rhabdomyosarcoma cancer cells proliferation in the dose-dependent manner after VPA, SAHA, or CDDP treatment (Figure 1). The $\mathrm{IC}_{50}$ values were the concentrations resulting in $50 \%$ cell growth inhibition by a $96-\mathrm{h}$ exposition to active agents as compared with control (untreated cells). IC $_{50}$ values for TE671 cell line treated with VPA, SAHA, CDDP was established as follows: $196.4 \mu \mathrm{g} / \mathrm{ml}$ for VPA, $0.052 \mu \mathrm{g} / \mathrm{ml}$ for SAHA and $0.591 \mu \mathrm{g} / \mathrm{ml}$ for CDDP (Table I).

Anti-proliferative effects of SAHA and VPA administered singly and in combination with CDDP to the TE671 cell line. The independent administration of CDDP, SAHA and VPA resulted in a clear-cut anti-proliferative effect in the 

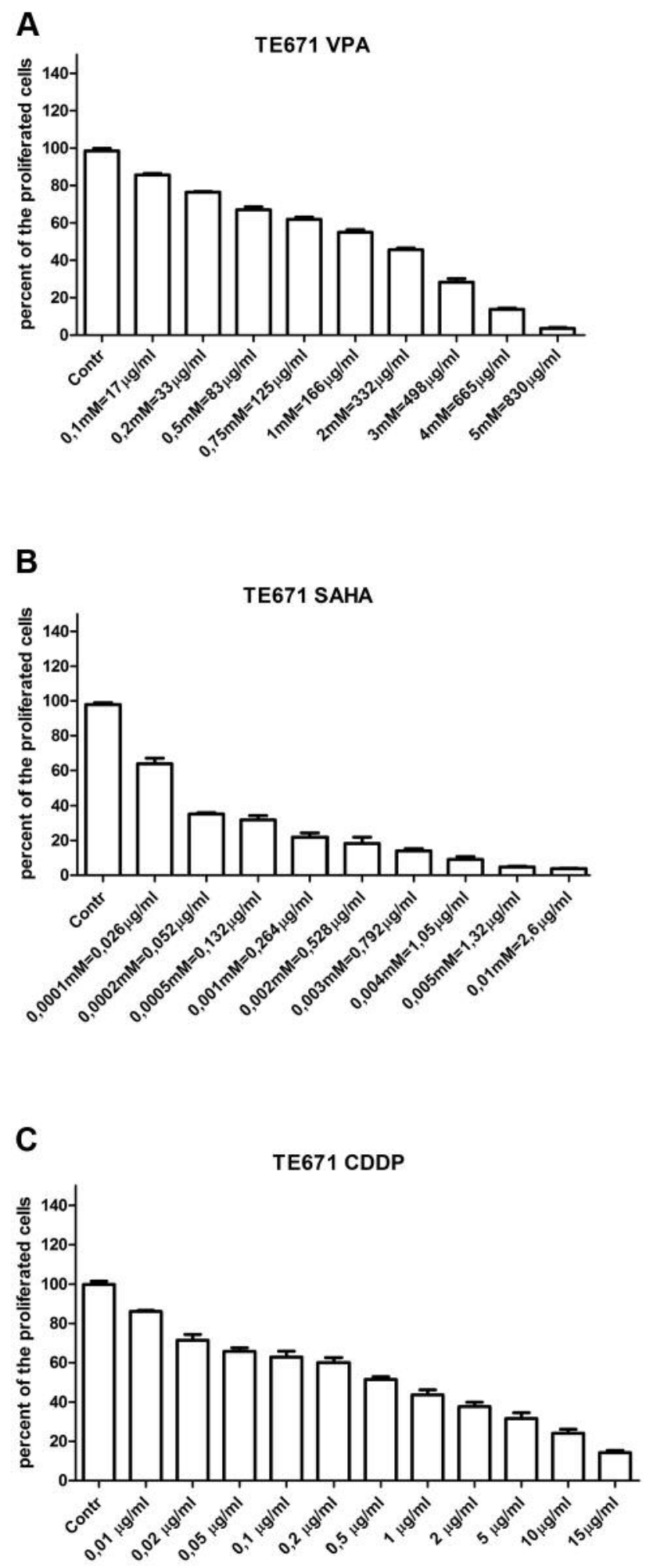

Figure 1. Inhibition of proliferation in TE671 cancer cells with (A) valproic acid (VPA), (B) suberoylanilide hydroxamic acid (SAHA) and (C) cisplatin (CDDP), analyzed by an MTT assay. Data represent mean optical densities \pm S.E.M., $\quad\left({ }^{*} p<0.05 ; * * p<0.01 ; * * * p<0.001\right.$ versus control; Student's test).
Table I. Anti-proliferative effects of CDDP, SAHA and VPA administered singly in the TE671 cancer cell line.

\begin{tabular}{lccccc}
\hline Drug & $\mathrm{IC}_{50}(\mu \mathrm{g} / \mathrm{ml})$ & $n$ & CFP & $p / q$ & Parallelism \\
\hline CDDP & $0.591 \pm 0.187$ & 48 & $0.363(\mathrm{q})$ & - & \\
SAHA & $0.052 \pm 0.028$ & 36 & $0.766(\mathrm{p} 1)$ & 2.110 & not parallel \\
VPA & $196.4 \pm 80.13$ & 60 & $0.801(\mathrm{p} 2)$ & 2.206 & not parallel \\
\hline
\end{tabular}

Results are presented as median inhibitory concentrations $\left(\mathrm{IC}_{50}\right.$ values in $\mu \mathrm{g} / \mathrm{ml} \pm$ S.E.M.) of CDDP, SAHA and VPA administered alone with respect to their anti-proliferative effects in the rhabdomyosarcoma cell line (TE671) measured in vitro by the MTT assay. $n$ - total number of items used at concentrations whose expected anti-proliferative effects ranged between 4 and 6 probits (16\% and 84\%); CFP - ( $q$ and $p$ ) curvefitting parameters; $p / q-$ ratio of $p$ and $q$ values. Test for parallelism between two dose-response effects (CDDP vs. SAHA and CDDP vs. VPA) was performed according to the procedure as described in details earlier (35).

rhabdomyosarcoma cell line TE671 (Figure 2A and B). Logprobit dose-response effects for CDDP, SAHA and VPA allowed for calculation of their $\mathrm{IC}_{50}$ values that amounted to $0.591 \pm 0.187 \mu \mathrm{g} / \mathrm{ml}, 0.052 \pm 0.028 \mu \mathrm{g} / \mathrm{ml}$ and $196.4 \pm 80.13$ $\mu \mathrm{g} / \mathrm{ml}$, respectively (Table I). The test for parallelism of dose-response effects between CDDP and SAHA and CDDP and VPA confirmed that the log-probit lines of these compounds were non-parallel to one another (Table I, Figure $2 \mathrm{~A}$ and $\mathrm{B})$.

Isobolographic analysis shows additive interactions between HDI and CDDP in TE671 cells. The combinations of CDDP with SAHA and CDDP with VPA (both, at the fixed-ratio of 1:1) produced the definite anti-proliferative effects in the TE671 cell line. The experimentally determined $\mathrm{IC}_{50 \mathrm{mix}}$ values for the two-drug mixture were $0.243 \pm 0.028 \mu \mathrm{g} / \mathrm{ml}$ for the combination of CDDP with SAHA (Table II, Figure 3A), and $127.7 \pm 21.26 \mu \mathrm{g} / \mathrm{ml}$ for the combination of CDDP with VPA (Table II, Figure 3B). With type I isobolographic analysis, no statistical difference was observed between the $\mathrm{IC}_{50 \text { mix }}$ and $\mathrm{IC}_{50 \text { add }}$ values with unpaired Student's $t$-test and thus, the analyzed interactions between CDDP and SAHA or VPA were additive (Table II).

\section{Discussion}

In the last years, little progress has been made in identifying new therapeutic agents and approaches to treat RMS (37). Multi-agent chemotherapy -mostly combined use of vincristine, dactinomycin, and cyclophosphamide (VAC)- has been the standard treatment for RMS for more than forty years. Introduction of other treatment systems like IVA (ifosfamide, vincristine and dactinomycin) or CEV (carboplatin, etoposide and vincristine), as well as IVE (ifosfamide, vincristine and 

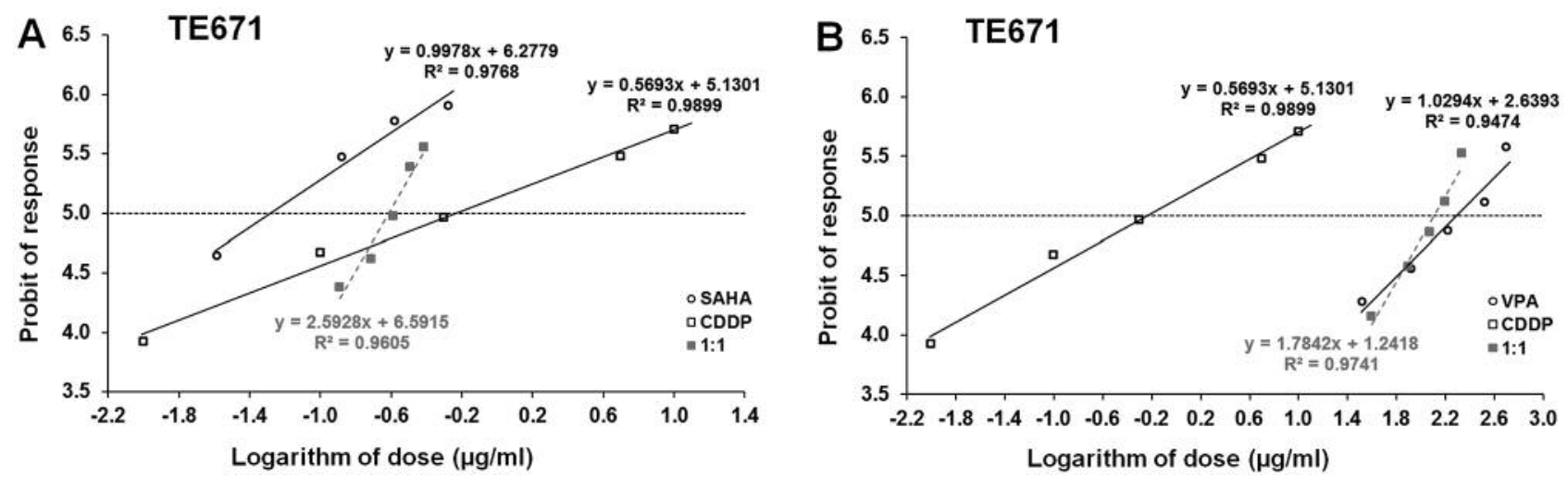

Figure 2. Log-probit dose-response effects for cisplatin (CDDP) and suberoylanilide hydroxamic acid (SAHA) (A), and for cisplatin (CDDP) and valproic acid (VPA) (B), administered both, separately and in combination at the fixed-ratio of 1:1, displaying the anti-cancer effects of the drugs in the rhabdomyosarcoma cell line TE671 measured in vitro by MTT assay. Logarithm of doses of CDDP, SAHA and VPA, when administered singly and in combination at the fixed-ratio 1:1 are placed on the abscissa, whereas the anti-proliferative effects evoked by these drugs and transformed to probits of response are placed on the ordinate of the Cartesian coordinate system according to Litchfield and Wilcoxon (1949) (33). Dose-response effects are linearly related and are presented on each graph; where $y$ - is the probit of response, and $x$ - is the logarithm (to the base 10) of a drug dose, $R^{2}$ - coefficient of determination.
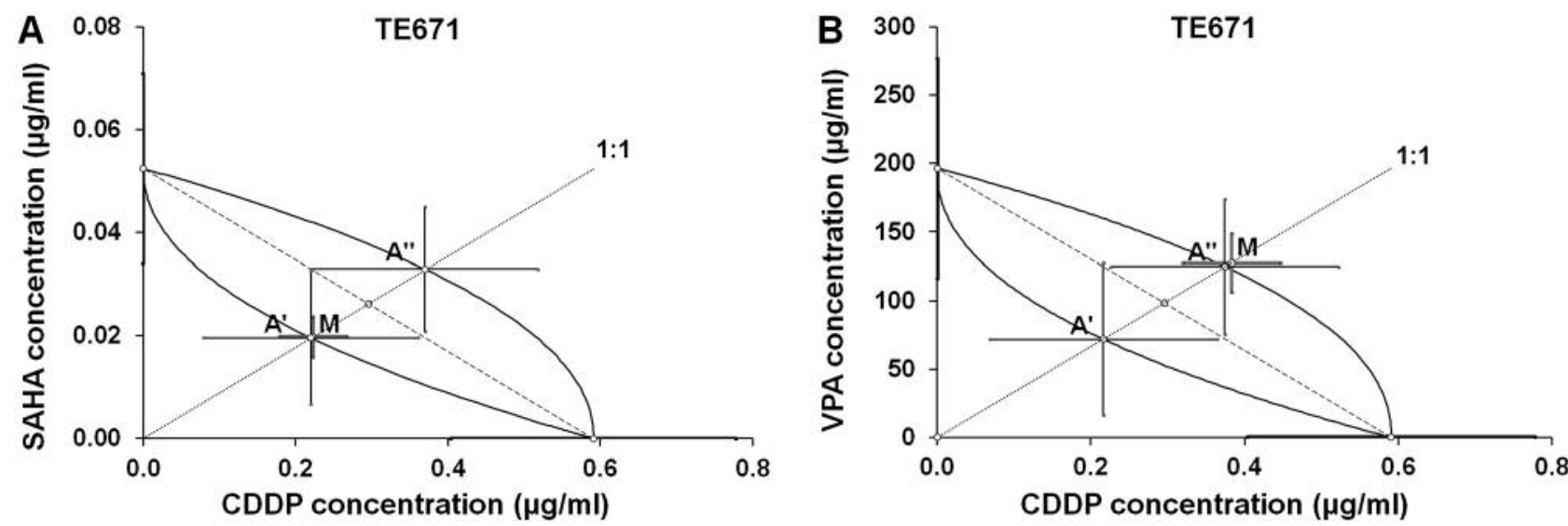

Figure 3. Isobolograms illustrating additive interactions between cisplatin (CDDP) and suberoylanilide hydroxamic acid (SAHA) (A), and cisplatin $(C D D P)$ and valproic acid (VPA) $(B)$ in terms of their anti-cancer effects in the rhabdomyosarcoma cell line TE671 measured in vitro by the MTT assay. Median inhibitory concentrations $\left(I C_{50}\right)$ for CDDP, SAHA and VPA are plotted graphically on the abscissa $(C D D P)$ and ordinate $(S A H A$

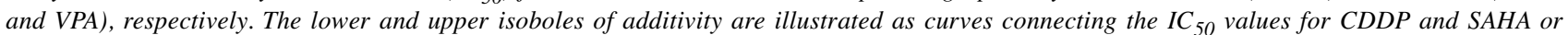
$V P A$. The line starting from the point $(0,0)$ corresponds to the fixed-ratio of 1:1 for the combination of CDDP with SAHA or VPA. Points A' and $A$ " depict the theoretically calculated $I C_{50}$ add values for both, lower and upper isoboles of additivity, whereas the point $M$ corresponds to the experimentally-derived $I C_{50 \text { mix }}$ value for the total dose of the mixture expressed as proportions of CDDP and SAHA or CDDP and VPA that produced a $50 \%$ anti-proliferative effect. For every $I C_{50}$ value the S.E.M. values are presented as horizontal and vertical error bars.

etoposide) did not improve survival or reduce the intensity of local therapy, but was associated with increased toxicity (38). Recent data suggest favorable response to platinum-based systemic chemotherapy for RMS treatment at different localizations in the body (39-42).

On the other hand, new generation of anticancer drugs -histone deacetylase inhibitors were introduced to the clinic for the treatment of some types of tumors (43). Pre-clinical studies showed potential of HDI use in the treatment of RMS. Second-generation histone deacetylase inhibitor JNJ26481585 induced mitochondrial-dependent apoptosis and suppressed tumor growth in vivo in two pre-clinical RMS models (44), whereas expression of $\mathrm{NAD}^{+}$dependent histone deacetylases sirtuins 1 and 2 was crucial for the survival of 
Jarzab et al: The Effect of Combined Treatment with Histone Deacetylase Inhibitors and Cisplatin

Table II. Type I isobolographic analysis of interactions between CDDP and SAHA or VPA at the fixed-ratio combination of 1:1 in the TE671 cancer cell line.

\begin{tabular}{lcccccc}
\hline Combination & $\mathrm{IC}_{50} \operatorname{mix}(\mu \mathrm{g} / \mathrm{ml})$ & $\mathrm{n}$ mix & ${ }^{\#} \mathrm{IC}_{50 \text { add }}(\mu \mathrm{g} / \mathrm{ml})$ & $n$ add & ${ }^{+} \mathrm{IC}_{50}$ add $(\mu \mathrm{g} / \mathrm{ml})$ & $n$ add \\
\hline CDDP+SAHA & $0.243 \pm 0.028$ & 120 & $0.240 \pm 0.154$ & 80 & $0.403 \pm 0.160$ \\
CDDP+VPA & $127.7 \pm 21.26$ & 120 & $72.11 \pm 55.83$ & 104 & $125.1 \pm 49.33$ \\
\hline
\end{tabular}

Results indicated median inhibitory concentrations $\left(\mathrm{IC}_{50}\right.$ values in $\mu \mathrm{g} / \mathrm{ml} \pm \mathrm{S}$.E.M.) of two-drug mixtures. (CDDP+SAHA and CDDP+VPA), determined either experimentally $\left(\mathrm{IC}_{50 \text { mix }}\right.$ ) or theoretically calculated as additive $\left(\mathrm{IC}_{50 \text { add }}\right.$ ), inhibiting proliferation in $50 \%$ of tested cells in the cancer cell line (TE671) measured in vitro by the MTT assay. $\mathrm{n}_{\text {mix }}$ - total number of items used at those concentrations whose expected antiproliferative effects ranged between $16 \%$ and $84 \%$ (i.e., 4 and 6 probits) for the experimental mixtures; $n$ add - total number of animals calculated for the additive mixture of the drugs examined $\left(n_{\text {add }}=n_{\text {CDDP }}+n_{\text {SAHA }-4}\right)$ or $\left(n_{\text {add }}=n_{\text {CDDP }}+n_{\text {VPA }} 4\right)$; ${ }^{*}-\mathrm{IC}_{50}$ add value calculated for the lower line of additivity; ${ }^{+}-\mathrm{IC}_{50}$ add value calculated for the upper line of additivity.

rhabdomyosarcoma cell, and pharmacological inhibition of sirtuins impaired the autophagy process and induced tumor cell death (45). Finally, SAHA inhibited growth of RMS cells (18) and significantly increased chemotherapeutic druginduced apoptosis in both embryonal and alveolar RMS cell lines, including several anticancer agents that are used in the clinic for the treatment of RMS such as doxorubicin, etoposide, vincristine and cyclophosphamide (46).

In the present study, we analyzed efficacy of treatment and the type of pharmacological drug-drug interaction of two HDIs (SAHA or VPA) with cisplatin to assess potential application of combined treatment in TE671 rhabdomyosarcoma cells. To the best of our knowledge, such combinations had not been tested in RMS cells, but were shown to be very effective in other cancer cells types, including non-small cell lung cancer cells (47), oralsquamous cell carcinoma (48), as well as in platinumresistant ovarian cancer cells (49). Our experiments revealed that the combination of CDDP with SAHA or CDDP with VPA showed additive interaction on the viability of TE-671 cells. This assessment was revealed by using advanced isobolographic analysis of drug-drug interaction. This very efficient method is seldom performed to establish pharmacological type of drug-drug interaction in cancerrelated studies. Instead, usually simple correlations between tested compounds are demonstrated, where only limited number of random chosen doses are selected, without precise method of drug-type interaction analysis $(50,51)$.

By showing additive interaction of tested compounds in RMS cells, our results strongly suggest application of such drug combinations in other pre-clinical models, including animal xenografts. Additionally, VPA is a widely used antiepileptic drug, with known pharmacokinetics and adverse effects (52), thereby no toxicity studies are necessary. Although direct cellular or molecular mechanism responsible for observed anti-cancer effect of HDIs and CDDP is not known, some genetic and epigenetic events related to histone acetylation and associated with RMS progression were recently discovered, confirming potential use of HDIs in RMS treatment. In ERMS, mutations in BCL-6 co-repressor (BCOR), which encodes a transcriptional repressor that interacts with histone deacetylases (HDACs) was confirmed $(37,53)$. It was also reported, that transcriptional suppression of the Pax3-FOXO1 allele by HDAC inhibitor entinostat resulted in much more favorable prognosis in ARMS animal model (54). Finally, vironostat was recently discovered as an agent that inhibits RMS tumor growth in vivo, induces apoptosis and inhibits invasion of RD and Rh30 RMS cell lines through a novel, ROS-dependent molecular mechanism of action due to epigenetic repression of $\mathrm{cMyc}$ and subsequent downregulation of SP transcription factors independent of histone acetylation (55). All these data suggest that HDIs could be promising anticancer agents for RMS, especially when combined with other cytostatic drugs or treatment strategies, as it was demonstrated in other cancers types. Our previous study proved that combination therapy of SAHA or VPA with CDDP increased apoptosis and cell-cycle arrest in MCF7, T47D and MDA-MB-231 human breast cancer cell lines, enabling to use lower doses of both drugs to obtain augmented anticancer effect (34). Our recent results were consistent with previously reported. Moreover, they were in accordance to published data that revealed SAHA inhibited cell proliferation and intensified the anti-proliferative effects of CDDP both in vitro (head and neck cancer cells), and in vivo (decreased tumor metastasis in mouse xenograft models) (56). The mechanism responsible for the combining treatment that increase CDDP sensitivity in cancer cells could be related to amplification of the accessibility of DNA to CDDP and transcriptional regulators by the epigenetic changes mediated by HDIs (57).

In conclusion, our study using isobolographic method of pharmacological drug-drug interaction analysis proved that combined medication of HDIs with CDDP could be used in the treatment of rhabdomyosarcoma cancer cells to improve their antitumor effects and decrease their doses compared to those administered separately. 


\section{References}

1 Hiniker SM and Donaldson SS: Recent advances in understanding and managing rhabdomyosarcoma. F1000Prime Rep 7: 59, 2015.

2 Sun X, Guo W, Shen JK, Mankin HJ, Hornicek FJ and Duan Z: Rhabdomyosarcoma: Advances in Molecular and Cellular Biology. Sarcoma 2015: 232010, 2015.

3 Zhou DN, Yang QQ, Li ZL, Pan ZY and Deng YF: Head and neck rhabdomyosarcoma: follow-up results of four cases and review of the literature. Int J Clin Exp Pathol 8: 4277-4283, 2015.

4 Dasari S and Tchounwou PB: Cisplatin in cancer therapy: molecular mechanisms of action. Eur J Pharmacol 740: 364-378, 2014.

5 Stenzel-Bembenek A, Sagan D, Guz M and Stepulak A: [Single nucleotide polymorphisms in lung cancer patients and cisplatin treatment]. Postepy Hig Med Dosw 68: 1361-1373, 2014.

$6 \mathrm{Xu} \mathrm{XM,} \mathrm{Zhang} \mathrm{Y,} \mathrm{Qu} \mathrm{D,} \mathrm{Liu} \mathrm{HB,} \mathrm{Gu} \mathrm{X,} \mathrm{Jiao} \mathrm{GY} \mathrm{and} \mathrm{Zhao} \mathrm{L:}$ Combined anticancer activity of osthole and cisplatin in NCIH460 lung cancer cells in vitro. Exp Ther Med 5: 707-710, 2013.

7 Alizadehnohi M, Nabiuni M, Nazari Z, Safaeinejad Z and Irian $S$ : The synergistic cytotoxic effect of cisplatin and honey bee venom on human ovarian cancer cell line A2780cp. J Venom Res 3: 22-27, 2012.

8 Apostolou P, Toloudi M, Chatziioannou M, Ioannou E, Knocke DR, Nester J, Komiotis D and Papasotiriou I: Anvirzel in combination with cisplatin in breast, colon, lung, prostate, melanoma and pancreatic cancer cell lines. BMC Pharmacol Toxicol 14: 18, 2013.

9 Grabarska A, Dmoszynska-Graniczka M, Nowosadzka E and Stepulak A: Histone deacetylase inhibitors - molecular mechanisms of actions and clinical applications. Postepy Hig Med Dosw 67: 722-735, 2013.

10 Chun P: Histone deacetylase inhibitors in hematological malignancies and solid tumors. Arch Pharm Res 38: 933-949, 2015.

11 Liu N, Zhao LJ, Li XP, Wang JL, Chai GL and Wei LH: Histone deacetylase inhibitors inducing human cervical cancer cell apoptosis by decreasing DNA-methyltransferase 3B. Chin Med J 125: 3273-3278, 2012.

12 Witt O, Milde T, Deubzer HE, Oehme I, Witt R, Kulozik A, Eisenmenger A, Abel U and Karapanagiotou-Schenkel I: Phase I/II intra-patient dose escalation study of vorinostat in children with relapsed solid tumor, lymphoma or leukemia. Klin Pediatr 224: 398-403, 2012.

13 Straus DJ, Hamlin PA, Matasar MJ, Lia Palomba M, Drullinsky PR, Zelenetz AD, Gerecitano JF, Noy A, Hamilton AM, Elstrom $\mathrm{R}$, Wegner B, Wortman $\mathrm{K}$ and Cella D: Phase I/II trial of vorinostat with rituximab, cyclophosphamide, etoposide and prednisone as palliative treatment for elderly patients with relapsed or refractory diffuse large B-cell lymphoma not eligible for autologous stem cell transplantation. Br J Haematol 168: 663-670, 2015.

14 Burke MJ, Lamba JK, Pounds S, Cao X, Ghodke-Puranik Y, Lindgren BR, Weigel BJ, Verneris MR and Miller JS: A therapeutic trial of decitabine and vorinostat in combination with chemotherapy for relapsed/refractory acute lymphoblastic leukemia. Am J Hematol 89: 889-895, 2014.
15 Kirschbaum M, Gojo I, Goldberg SL, Bredeson C, Kujawski LA, Yang A, Marks P, Frankel P, Sun X, Tosolini A, Eid JE, Lubiniecki GM and Issa JP: A phase 1 clinical trial of vorinostat in combination with decitabine in patients with acute myeloid leukaemia or myelodysplastic syndrome. Br J Haematol 167: 185-193, 2014.

16 Haas NB, Quirt I, Hotte S, McWhirter E, Polintan R, Litwin S, Adams PD, McBryan T, Wang L, Martin LP, vonMehren M, Alpaugh RK, Zweibel J and Oza A: Phase II trial of vorinostat in advanced melanoma. Invest New Drugs 32: 526-534, 2014.

17 Mahalingam D, Mita M, Sarantopoulos J, Wood L, Amaravadi RK, Davis LE, Mita AC, Curiel TJ, Espitia CM, Nawrocki ST, Giles FJ and Carew JS: Combined autophagy and HDAC inhibition: a phase I safety, tolerability, pharmacokinetic, and pharmacodynamic analysis of hydroxychloroquine in combination with the HDAC inhibitor vorinostat in patients with advanced solid tumors. Autophagy 10: 1403-1414, 2014.

18 Kutko MC, Glick RD, Butler LM, Coffey DC, Rifkind RA, Marks PA, Richon VM and LaQuaglia MP: Histone deacetylase inhibitors induce growth suppression and cell death in human rhabdomyosarcoma in vitro. Clin Cancer Res 9: 5749-5755, 2003.

19 Vleeshouwer-Neumann T, Phelps M, Bammler TK, MacDonald JW, Jenkins I and Chen EY: Histone deacetylase inhibitors antagonize distinct pathways to suppress tumorigenesis of embryonal rhabdomyosarcoma. PloS One 10: e0144320, 2015.

20 Blattmann C, Oertel S, Ehemann V, Thiemann M, Huber PE, Bischof M, Witt O, Deubzer HE, Kulozik AE, Debus J and Weber KJ: Enhancement of radiation response in osteosarcoma and rhabdomyosarcoma cell lines by histone deacetylase inhibition. Int J Radiat Oncol Biol Phys 78: 237-245, 2010.

21 Blaheta RA and Cinatl J Jr.: Anti-tumor mechanisms of valproate: a novel role for an old drug. Med Res Rev 22: 492$511,2002$.

22 Cornago M, Garcia-Alberich C, Blasco-Angulo N, Vall-Llaura N, Nager M, Herreros J, Comella JX, Sanchis D and Llovera M: Histone deacetylase inhibitors promote glioma cell death by G2 checkpoint abrogation leading to mitotic catastrophe. Cell Death Dis 5: e1435, 2014.

23 Proske J, Walter L, Bumes E, Hutterer M, Vollmann-Zwerenz A, Eyupoglu IY, Savaskan NE, Seliger C, Hau P and Uhl M: Adaptive immune response to and survival effect of temozolomide- and valproic acid-induced autophagy in glioblastoma. Anticancer Res 36: 899-905, 2016.

24 Ahmadzadeh A, Khodadi E, Shahjahani M, Bertacchini J, Vosoughi $\mathrm{T}$ and Saki N: The Role of HDACs as Leukemia Therapy Targets using HDI. Int J Hematol Oncol Stem Cell Res 9: 203-214, 2015.

25 Ogura M, Ando K, Suzuki T, Ishizawa K, Oh SY, Itoh K, Yamamoto K, Au WY, Tien HF, Matsuno Y, Terauchi T, Yamamoto K, Mori M, Tanaka Y, Shimamoto T, Tobinai K and Kim WS: A multicentre phase II study of vorinostat in patients with relapsed or refractory indolent B-cell non-Hodgkin lymphoma and mantle cell lymphoma. Br J Haematol 165: 768-776, 2014.

26 Wawruszak A, Luszczki JJ, Grabarska A, Gumbarewicz E, Dmoszynska-Graniczka $M$, Polberg $K$ and Stepulak A: Assessment of interactions between cisplatin and two histone deacetylase inhibitors in MCF7, T47D and MDA-MB-231 human breast cancer cell lines - an isobolographic analysis. PloS One 10: e0143013, 2015. 
27 Zhou C, Ji J, Shi M, Yang L, Yu Y, Liu B, Zhu Z and Zhang J: Suberoylanilide hydroxamic acid enhances the antitumor activity of oxaliplatin by reversing the oxaliplatininduced Src activation in gastric cancer cells. Mol Med Rep 10: 2729-2735, 2014.

$28 \mathrm{Wu}$ Z, Ma C, Shan Z, Ju Y, Li S and Zhao Q: Histone deacetylase inhibitors suppress the growth of human osteosarcomas in vitro and in vivo. J BUON 18: 1032-1037, 2013.

29 Han JY, Lee SH, Lee GK, Yun T, Lee YJ, Hwang KH, Kim JY and Kim HT: Phase I/II study of gefitinib (Iressa((R))) and vorinostat (IVORI) in previously treated patients with advanced non-small cell lung cancer. Cancer Chemother Pharmacol 75: 475-483, 2015.

30 Ecke I, Petry F, Rosenberger A, Tauber S, Monkemeyer S, Hess I, Dullin C, Kimmina S, Pirngruber J, Johnsen SA, Uhmann A, Nitzki F, Wojnowski L, Schulz-Schaeffer W, Witt $\mathrm{O}$ and Hahn $\mathrm{H}$ : Antitumor effects of a combined 5-aza2 'deoxycytidine and valproic acid treatment on rhabdomyosarcoma and medullo-blastoma in Ptch mutant mice. Cancer Res 69: 887-895, 2009.

31 Jarzab A, Grabarska A, Kielbus M, Jeleniewicz W, DmoszynskaGraniczka M, Skalicka-Wozniak K, Sieniawska E, Polberg K and Stepulak A: Osthole induces apoptosis, suppresses cell-cycle progression and proliferation of cancer cells. Anticancer Res 34: 6473-6480, 2014.

32 Gessner PK: Isobolographic analysis of interactions: an update on applications and utility. Toxicology 105: 161-179, 1995.

33 Litchfield JT Jr. and Wilcoxon F: A simplified method of evaluating dose-effect experiments. J Pharmacol Exp Ther 96: 99-113, 1949.

34 Luszczki JJ: Isobolographic analysis of interaction between drugs with nonparallel dose-response relationship curves: a practical application. Naunyn Schmiedebergs Arch Pharmacol 375: 105-114, 2007.

35 Luszczki JJ, Filip D and Czuczwar SJ: Additive interactions of pregabalin with lamotrigine, oxcarbazepine and topiramate in the mouse maximal electroshock-induced seizure model: a type I isobolographic analysis for non-parallel dose-response relationship curves. Epilepsy Res 91: 166-175, 2010.

36 Tallarida RJ: Drug synergism: its detection and applications. J Pharmacol Exp Ther 298: 865-872, 2001.

37 Kashi VP, Hatley ME and Galindo RL: Probing for a deeper understanding of rhabdomyosarcoma: insights from complementary model systems Nat Rev Cancer 15: 426-439, 2015.

38 Hawkins DS, Gupta AA and Rudzinski ER: What is new in the biology and treatment of pediatric rhabdomyosarcoma? Curr Opin Pediatr 26: 50-56, 2014.

39 Ishi Y, Yamaguchi S, Iguchi A, Cho Y, Ohshima J, Hatanaka KC, Takakuwa E, Kobayashi H, Terasaka S and Houkin K: Primary pineal rhabdomyosarcoma successfully treated by high-dose chemotherapy followed by autologous peripheral blood stem cell transplantation: case report. J Neurosurg Pediatr 18: 41-45, 2016.

40 Jeong Y, Cheon J, Kim TO, Lim DH, Lee S, Cho YM, Hong JH and Lee JL: Conventional cisplatin-based combination chemotherapy is effective in the treatment of metastatic spermatocytic seminoma with extensive rhabdomyo-sarcomatous transformation. Cancer Res Treat 47: 931-936, 2015.

41 Agarwala S: Primary malignant liver tumors in children. Indian J Pediatr 79: 793-800, 2012
42 Wagemans J, Beuselinck B, Nuyts S, Sciot R, Delaere P, Vander Poorten V, Dumez H, Hermans R, Schoffski P, Van den Bogaert $\mathrm{W}$, Jorissen $\mathrm{M}$ and Clement PM: A case series of embryonal rhabdomyosarcoma of the head and neck in adults. Acta Clin Belg 65: 404-410, 2010.

43 Qiu X, Xiao X, Li N and Li Y: Histone deacetylases inhibitors (HDACis) as novel therapeutic application in various clinical diseases. Prog Neuropsychopharmacol Biol Psychiatry 72: 6072, 2017.

44 Heinicke U, Kupka J, Fichter I and Fulda S: Critical role of mitochondria-mediated apoptosis for JNJ-26481585-induced antitumor activity in rhabdomyosarcoma. Oncogene 35: 3729$3741,2016$.

45 Ma L, Maruwge W, Strambi A, D’Arcy P, Pellegrini P, Kis L, de Milito A, Lain S and Brodin B: SIRT1 and SIRT2 inhibition impairs pediatric soft tissue sarcoma growth. Cell Death Dis 5: e1483, 2014.

46 Heinicke U and Fulda S: Chemosensitization of rhabdomyosarcoma cells by the histone deacetylase inhibitor SAHA. Cancer Lett 351: 50-58, 2014.

47 Feng J, Zhang S, Wu K, Wang B, Wong JY, Jiang H, Xu R, Ying L, Huang H, Zheng X, Chen X and Ma S: Combined effects of suberoylanilide hydroxamic acid and cisplatin on radiation sensitivity and cancer cell invasion in non-small cell lung cancer. Mol Cancer Ther 15: 842-853, 2016.

48 Suzuki M, Endo M, Shinohara F, Echigo S and Rikiishi H: Enhancement of cisplatin cytotoxicity by SAHA involves endoplasmic reticulum stress-mediated apoptosis in oral squamous cell carcinoma cells. Cancer Chemother Pharmacol 64: 1115-1122, 2009.

49 Ong PS, Wang XQ, Lin HS, Chan SY and Ho PC: Synergistic effects of suberoylanilide hydroxamic acid combined with cisplatin causing cell cycle arrest independent apoptosis in platinum-resistant ovarian cancer cells. Int J Oncol 40: 17051713, 2012.

50 Kim MS, Blake M, Baek JH, Kohlhagen G, Pommier Y and Carrier F: Inhibition of histone deacetylase increases cytotoxicity to anticancer drugs targeting DNA. Cancer Res 63: 7291-7300, 2003.

51 Chien CW, Yao JH, Chang SY, Lee PC and Lee TC: Enhanced suppression of tumor growth by concomitant treatment of human lung cancer cells with suberoylanilide hydroxamic acid and arsenic trioxide. Toxicol Appl Pharmacol 257: 59-66, 2011.

52 Nakashima H, Oniki K, Nishimura M, Ogusu N, Shimomasuda M, Ono T, Matsuda K, Yasui-Furukori N, Nakagawa K, Ishitsu $\mathrm{T}$ and Saruwatari J: Determination of the optimal concentration of valproic acid in patients with epilepsy: a population pharmacokinetic-pharmacodynamic analysis. PloS One 10: e0141266, 2015.

53 Shern JF, Chen L, Chmielecki J, Wei JS, Patidar R, Rosenberg M, Ambrogio L, Auclair D, Wang J, Song YK, Tolman C, Hurd L, Liao H, Zhang S, Bogen D, Brohl AS, Sindiri S, Catchpoole D, Badgett T, Getz G, Mora J, Anderson JR, Skapek SX, Barr FG, Meyerson M, Hawkins DS and Khan J: Comprehensive genomic analysis of rhabdomyosarcoma reveals a landscape of alterations affecting a common genetic axis in fusion-positive and fusion-negative tumors. Cancer Discov 4: 216-231, 2014.

54 Abraham J, Nunez-Alvarez Y, Hettmer S, Carrio E, Chen HI, Nishijo K, Huang ET, Prajapati SI, Walker RL, Davis S, Rebeles J, Wiebush H, McCleish AT, Hampton ST, Bjornson CR, Brack AS, Wagers AJ, Rando TA, Capecchi MR, Marini FC, Ehler BR, 
Zarzabal LA, Goros MW, Michalek JE, Meltzer PS, Langenau DM, LeGallo RD, Mansoor A, Chen Y, Suelves M, Rubin BP and Keller C: Lineage of origin in rhabdomyosarcoma informs pharmacological response. Genes Dev 28: 1578-1591, 2014.

55 Hedrick E, Crose L, Linardic CM and Safe S: Histone deacetylase inhibitors inhibit rhabdomyosarcoma by reactive oxygen species-dependent targeting of specificity protein transcription factors. Mol Cancer Ther 14: 2143-2153, 2015.

56 Kumar B, Yadav A, Lang JC, Teknos TN and Kumar P: Suberoylanilide hydroxamic acid (SAHA) reverses chemoresistance in head and neck cancer cells by targeting cancer stem cells via the downregulation of nanog. Genes Cancer 6: 169-181, 2015.

57 Jin KL, Park JY, Noh EJ, Hoe KL, Lee JH, Kim JH and Nam $\mathrm{JH}$ : The effect of combined treatment with cisplatin and histone deacetylase inhibitors on HeLa cells. Gynecol Oncol 21: 262268, 2010.

Received January 5, 2017

Revised February 3, 2017

Accepted February 9, 2017 